\title{
Shear-Induced Crystallization of Star and Linear Poly(L-lactide)s
}

\author{
Joanna Bojda *, Ewa Piorkowska, Grzegorz Lapienis (D) and Adam Michalski \\ Centre of Molecular and Macromolecular Studies, Polish Academy of Sciences, Sienkiewicza 112, \\ 90-363 Lodz, Poland; epiorkow@cbmm.lodz.pl (E.P.); lapienis@cbmm.lodz.pl (G.L.); \\ michadam@cbmm.lodz.pl (A.M.) \\ * Correspondence: jbojda@cbmm.lodz.pl
}

Citation: Bojda, J.; Piorkowska, E.; Lapienis, G.; Michalski, A. Shear-Induced Crystallization of Star and Linear Poly(L-lactide)s. Molecules 2021, 26, 6601. https://doi.org/ $10.3390 /$ molecules26216601

Academic Editor: Ivan Gitsov

Received: 21 September 2021

Accepted: 22 October 2021

Published: 31 October 2021

Publisher's Note: MDPI stays neutral with regard to jurisdictional claims in published maps and institutional affiliations.

Copyright: (c) 2021 by the authors. Licensee MDPI, Basel, Switzerland. This article is an open access article distributed under the terms and conditions of the Creative Commons Attribution (CC BY) license (https:// creativecommons.org/licenses/by/ $4.0 /)$.

\begin{abstract}
The influence of macromolecular architecture on shear-induced crystallization of poly(Llactide) (PLLA) was studied. To this aim, three star PLLAs, 6-arm with $\mathrm{M}_{\mathrm{w}}$ of 120 and $245 \mathrm{~kg} / \mathrm{mol}$, 4-arm with $\mathrm{M}_{\mathrm{W}}$ of $123 \mathrm{~kg} / \mathrm{mol}$, and three linear PLLAs with $\mathrm{M}_{\mathrm{W}}$ of 121, 240 and $339 \mathrm{~kg} / \mathrm{mol}$, were synthesized and examined. The PLLAs were sheared at 170 and $150{ }^{\circ} \mathrm{C}$, at $5 / \mathrm{s}, 10 / \mathrm{s}$ and $20 / \mathrm{s}$ for $20 \mathrm{~s}, 10 \mathrm{~s}$ and $5 \mathrm{~s}$, respectively, and then cooled at 10 or $30^{\circ} \mathrm{C} / \mathrm{min}$. Shear-induced crystallization during cooling was followed by a light depolarization method, whereas the crystallized specimens were examined by DSC, 2D-WAXS, 2D-SAXS and SEM. The effect of shear depended on the shearing conditions, cooling rate and polymer molar mass but it was also affected by the macromolecular architecture. The shear-induced crystallization of linear PLLA with $\mathrm{M}_{\mathrm{w}}$ of $240 \mathrm{~kg} / \mathrm{mol}$ was more intense than that of the 6-arm polymer with similar $\mathrm{M}_{\mathrm{w}}$, most possibly due to its higher $\mathrm{M}_{\mathrm{z}}$. However, the influence of shear on the crystallization of the star polymers with $\mathrm{M}_{\mathrm{W}}$ close to $120 \mathrm{~kg} / \mathrm{mol}$ was stronger than on that of their linear analog. This was reflected in higher crystallization temperature, as well as crystallinity achieved during cooling.
\end{abstract}

Keywords: poly(L-lactide); star poly(L-lactide); shear-induced crystallization; crystallinity; fibrillar nuclei

\section{Introduction}

In recent decades, bio-based polymers derived from annually renewable resources have drawn increasing attention [1], as biomass is the only source of available renewable carbon. Among them, polylactide (PLA) is the most promising polymer for the replacement of conventional thermoplastics, especially because it is also biodegradable (compostable) and can be used for a wide range of applications, including biomedical products, textiles, daily appliances, packaging, items used in agriculture and engineering [1-5].

Amorphous PLA with the glass transition temperature, $\mathrm{T}_{\mathrm{g}}$, in the range of $55-60{ }^{\circ} \mathrm{C}$, is stiff and brittle at room temperature. The crystallizability of PLA strongly depends on its enantiomeric composition and worsens with increasing content of repeating units of different chirality in the chain [6,7]. However, even optically pure poly(L-lactide) (PLLA), if cooled sufficiently fast, remains amorphous and vitrifies. Then, upon heating from the glassy state, such amorphous PLLA can cold-crystallize. However, not only the enantiomeric composition but also other factors, including molar mass and macromolecular architecture, for instance, branching or star structure, are also important and influence the crystallization of PLA. Depending on crystallization temperature, PLA chains crystallize from melt in the ordered alpha or disordered alpha' orthorhombic forms [8], which can be identified not only by wide angle X-ray scattering but also by Raman spectroscopy or nuclear magnetic resonance spectroscopy $[9,10]$.

Star polymers are especially interesting for many applications, for example in biomedicine or engineering $[11,12]$. Their rheological, thermal and mechanical properties can differ from those of their linear counterparts [11,13]. In addition, processing of star polymers can 
be carried out at lower temperatures than their linear analogs, which could be beneficial, especially in the case of polymers prone to thermal degradation like PLAs.

Star PLLAs were most often obtained by the bulk polymerization of cyclic lactide conducted at a temperature above the melting point of the monomer $\left(\sim 99^{\circ} \mathrm{C}\right)$, in the presence of initiators with hydroxyl end groups, with stannous octoate $\left(\mathrm{Sn}(\mathrm{Oct})_{2}\right)$ as a catalyst [14-19]. Crystallization of star PLLAs was found to be affected by their molar masses and numbers of arms. Usually, PLLAs with number average molar masses, $M_{n}$, below $100 \mathrm{~kg} / \mathrm{mol}$ were analyzed. The consequences of the relatively small molar mass of star PLLA are short arm length resulting in a small number or even absence of entanglements and a large number of chain ends as well as branching points. The presence of branching points, initiator moieties, especially bulky ones, in the middle of macromolecules, hydroxyl chain end groups enhancing hydrogen bonding, and chain directional change at the branching points, are the factors disturbing the segmental mobility [11,20]. Moreover, the branching points have to be excluded from the crystalline regions [21]. For example, for PLLAs with $\mathrm{M}_{\mathrm{n}}$ about $35 \mathrm{~kg} / \mathrm{mol}$, nonisothermal crystallization peak temperature, $\mathrm{T}_{\mathrm{c}}$, and overall isothermal crystallization rate decreased upon the increasing number of arms up to six [22]. Moreover, an increase of $\mathrm{T}_{\mathrm{g}}$, cold crystallization peak temperature, $\mathrm{T}_{\mathrm{cc},}$ accompanied by a decrease of melting peak temperature, $\mathrm{T}_{\mathrm{m}}$, and crystal growth rate of 3-arm PLLAs, with $\mathrm{M}_{\mathrm{n}}$ in the range of 13 to $63 \mathrm{~kg} / \mathrm{mol}$, were observed, as compared with those of linear PLLAs [21]. It is worth noting that crystallization of 6-arm PLLAs was rarely examined, and the studies were limited to polymers with $M_{n}$ per one arm below $10 \mathrm{~kg} / \mathrm{mol}$. For instance, it was found [23] that for 1-, 2-, 4- and 6-arm PLLAs, $\mathrm{T}_{\mathrm{m}}, \mathrm{T}_{\mathrm{cc}}$, and crystallinity, $\chi_{c}$, decreased with increasing number of arms at a fixed $\mathrm{M}_{\mathrm{n}}$. Recently, Bojda et al. [24] synthesized three star PLLAs, two 6-arm with weight average molar masses, $\mathrm{M}_{\mathrm{w}}$, of 120 and $245 \mathrm{~kg} / \mathrm{mol}$ and one 4 -arm with $\mathrm{M}_{\mathrm{w}}$ of $123 \mathrm{~kg} / \mathrm{mol}$, and compared their crystallization with that of linear ones with $\mathrm{M}_{\mathrm{w}}$ of 121,291 and $339 \mathrm{~kg} / \mathrm{mol}$. At $\mathrm{M}_{\mathrm{w}}$ close to $120 \mathrm{~kg} / \mathrm{mol}$ the star architecture decreased the crystal growth rate in the temperature range of $120-145^{\circ} \mathrm{C}$. Crystal growth of PLLAs with $\mathrm{M}_{\mathrm{w}}>200 \mathrm{~kg} / \mathrm{mol}$ was the slowest and unaffected by the macromolecular architecture. The slow crystal growth in these PLLAs resulted in their weak crystallization during cooling.

In turn, it is long known that the crystallization of polymers, including PLAs, is strongly influenced by flow, which plays a vital role during industrial processing. The flowinduced macromolecular orientation can strongly affect the crystallization kinetics and the resulting structure, which are controlled by the interplay between crystallization and chain relaxation. The fundamental processes governing the flow-induced crystallization of polymer melts were discussed by many authors [25-27]. The shear-induced crystallization strongly depends on the temperature of shearing, $\mathrm{T}_{\mathrm{s}}$, shear rate, $\dot{\gamma}$, and total strain. It is believed [28] that to induce the point-like nuclei and fibrillar nuclei, the shear rate has to exceed the inverse reptation time and the inverse Rouse relaxation time of the high molar mass tail, respectively, although when the flow is strong enough, but too short, intermediate regimes were also defined. It is worth noting that others postulated that mechanical work is a controlling parameter $[26,29,30]$. A very important factor is the polymer molecular characteristic, especially the high molar mass tail is crucial due to the vital role of the longest macromolecules in the flow-induced crystallization. [26,31,32]. Similarly to other polymers, the enhancement of point-like nucleation, formation of oriented nuclei and shish-kebab structures induced by shear were observed in PLAs [33-35]. The effect of shear on both isothermal [34-37] and nonisothermal crystallization of PLAs was studied. Bojda et al. [36] demonstrated that smaller content of D-lactide enhanced the effect of shear on nonisothermal crystallization on PLA and that higher crystallinity degree developed during slower post-shearing cooling. In turn, Kim et al. [38] compared shear-induced crystallization of linear and 4-arm PLLAs with $\mathrm{M}_{\mathrm{w}}$ of about $2 \mathrm{~kg} / \mathrm{mol}$ and found that that of the latter was slightly faster. 
To the best of our knowledge, the effect of shear flow on the crystallization of star PLLAs with higher molar masses was not investigated. Only shear-induced isothermal crystallization of PLAs with long chain branching (LCB), prepared by $\gamma$ irradiation, was studied in $[39,40]$. It was demonstrated that the shear-induced nucleation density in LCB PLA was strongly enhanced in comparison to linear PLA and increased with increasing LCB degree. Moreover, the transformation from spherulitic to oriented crystalline morphologies was observed. It was concluded that the shear-induced formation of the oriented crystalline morphology of LCB PLAs was related to the hindering of relaxation of the stretched LCB macromolecular chain network.

In the present study, shear-induced nonisothermal crystallization of star PLLAs with $\mathrm{M}_{\mathrm{W}}$ close to 120 and $240 \mathrm{~kg} / \mathrm{mol}$ was studied and compared with that of their linear analogs. In addition, the crystallization of linear PLLA with $\mathrm{M}_{\mathrm{w}}$ of $339 \mathrm{~kg} / \mathrm{mol}$ was also examined. The polymers were sheared at 170 and $150^{\circ} \mathrm{C}$ and cooled at 10 or $30^{\circ} \mathrm{C} / \mathrm{min}$. The crystallization was followed by a light depolarization technique, whereas the crystallized specimens were ex-situ examined with scanning electron microscopy (SEM), differential scanning calorimetry (DSC), small- and wide-angle X-ray scattering (2D-SAXS and 2DWAXS).

\section{Materials and Methods}

Linear PLLAs having at one chain end benzyl alcohol and star-shaped PLLAs having as a core: di(trimethylolpropane) (4-arm PLLA-OH) or dipentaerythritol (6-arm PLA$\mathrm{OH})$, were synthesized in bulk at $130{ }^{\circ} \mathrm{C}$ by coordination polymerization using hydroxyl compound as an initiator and stannous octoate as a catalyst, as described previously [24]. The resulting PLLAs were dissolved in dichloromethane and precipitated into methanol, separated by filtration, and washed several times with methanol. The polymers were characterized with size exclusion chromatography (SEC) and ${ }^{1} \mathrm{H}$ NMR. After purification, the polymers were stabilized with $0.2 \mathrm{wt}$ \% of Irganox 1010 and $0.2 \mathrm{wt}$ \% of Irganox 1024, both from BASF (Ludwigshafen, Germany). The details of polymerization, purification, characterization and stabilization were previously described [19,24,41,42].

The average molar masses, number, $M_{n}$, weight, $M_{w}$, and z-average, $M_{z}$, and dispersity of linear and star-shaped PLLAs measured by SEC in dichloromethane are given in Table 1.

Table 1. The average molar masses, number, $M_{n}$, weight, $M_{w}$, and z-average, $M_{z}$, and dispersity $\mathrm{M}_{\mathrm{w}} / \mathrm{M}_{\mathrm{n}}$ of star and linear PLLAs.

\begin{tabular}{|c|c|c|c|c|}
\hline Sample Code & $M_{w}(\mathrm{~kg} / \mathrm{mol})$ & $M_{n}(\mathrm{~kg} / \mathrm{mol})$ & $M_{z}(\mathrm{~kg} / \mathrm{mol})$ & $\mathbf{M}_{\mathrm{w}} / \mathbf{M}_{\mathrm{n}}$ \\
\hline L121 & 121 & 81 & 194 & 1.5 \\
\hline L240 & 240 & 157 & 414 & 1.3 \\
\hline L339 & 339 & 257 & 495 & 1.3 \\
\hline $4 S 123$ & 123 & 97 & 152 & 1.3 \\
\hline $6 S 120$ & 120 & 80 & 162 & 1.5 \\
\hline $6 S 245$ & 245 & 183 & 294 & 1.3 \\
\hline
\end{tabular}

For studies of crystallization, $200 \mu \mathrm{m}$ thick films were compression moulded at $200{ }^{\circ} \mathrm{C}$ for $3 \mathrm{~min}$ in a hydraulic press and quenched to room temperature, RT, between metal blocks.

Flow-induced crystallization was carried out in the Linkam CSS-450 optical shearing system (Linkam, Waterfield, UK) mounted in a polarizing light microscope (PLM) Nikon Eclipse 80i equipped with Nikon DS Fi1 video camera. The films were: heated to $210{ }^{\circ} \mathrm{C}$ at $30{ }^{\circ} \mathrm{C} / \mathrm{min}$ and held at $210{ }^{\circ} \mathrm{C}$ for $3 \mathrm{~min}$ to erase the thermal history. Next the films were cooled at $30{ }^{\circ} \mathrm{C} / \mathrm{min}$ to $\mathrm{T}_{\mathrm{s}}$ of 170 or $150{ }^{\circ} \mathrm{C}$ and sheared at a rate, $\dot{\gamma}$, of 5,10 and $20 / \mathrm{s}$ for 20,10 and $5 \mathrm{~s}$, respectively to reach the same strain of 100 . After shearing, they were cooled to RT at a rate, $\mathrm{v}$, of 10 or $30^{\circ} \mathrm{C} / \mathrm{min}$. The shearing conditions were selected based 
on preliminary studies. Control specimens were subjected to a similar thermal treatment in quiescent conditions; they were held at $\mathrm{T}_{\mathrm{s}}$ for $20 \mathrm{~s}$ without shearing.

The conversion of melt into the crystalline phase was followed using the light depolarization method. The intensity of transmitted depolarized light was measured during cooling and the relative volume conversion degree, $\alpha_{\mathrm{vr}}(\mathrm{T})$, was calculated according to the expression:

$$
\alpha_{v r}(T)=\left[\mathrm{I}(\mathrm{T})-\mathrm{I}\left(\mathrm{T}_{\mathrm{o}}\right)\right] /\left[\mathrm{I}\left(\mathrm{T}_{\mathrm{e}}\right)-\mathrm{I}\left(\mathrm{T}_{\mathrm{o}}\right)\right]
$$

where: $\mathrm{I}(\mathrm{T})$ denotes the intensity of transmitted depolarized light at temperature $\mathrm{T}$, whereas $\mathrm{T}_{\mathrm{o}}$ and $\mathrm{T}_{\mathrm{e}}$ are the initial temperature and the final temperature of the measurement.

In the plate-plate geometry, shear rate varies along a radius, hence for ex-situ examination, specimens were cut from the films at proper distances from the centers, at which shear rates were equal to the selected values.

Crystallinity and thermal properties of the specimens were analyzed with differential scanning calorimetry (DSC) using TA Instrument DSC TA Q20 (New Castle, USA) during heating at $5{ }^{\circ} \mathrm{C} / \mathrm{min}$ from $\mathrm{RT}$, under nitrogen flow.

Crystal orientation in the films was examined with 2D-WAXS in the transmission mode, using a WAXS camera coupled to an X-ray generator (sealed-tube, fine point $\mathrm{CuK} \alpha$ source, Ni filtered, operating at $50 \mathrm{kV}$ and $35 \mathrm{~mA}$ ) from Philips (Eindhoven, Netherlands). The incident beam was normal to the film plane. The lamellar structure was probed with 2D small angle X-ray scattering (2D-SAXS). Kiessig-type camera with the sample-detector distance of $1.2 \mathrm{~m}$ was coupled to GeniX Cu-LD X-ray system from Xenocs (Grenoble, France), with $\mathrm{CuK} \alpha$ source operating at $50 \mathrm{kV}$ and $1 \mathrm{~mA}$. The incident beam was normal to the film plane. The scattering patterns were recorded with Pilatus 100K solid-state detector from Dectris (Baden, Switzerland).

To reveal their internal structure, selected sheared PLLA specimens were cut across their thickness parallel to the shearing direction, and the exposed surfaces were analyzed with scanning electron microscopy (SEM) using Jeol JSM-5500 LV (Tokyo, Japan). Before the examination, the specimens were etched according to the known method [36,43], at $37^{\circ} \mathrm{C}$, in a solution of $61 \mathrm{mg}$ of Trizma base, $2 \mathrm{mg}$ of sodium azide and $4 \mathrm{mg}$ of Proteinase $\mathrm{K}$ (all from Sigma-Aldrich, St. Louis, MO, USA) in $5 \mathrm{~mL}$ of distilled water. After appropriate washing and drying, the specimens were sputtered with gold.

\section{Results and Discussion}

\subsection{Crystallization}

Exemplary DSC heating thermograms of star-shaped and linear PLLAs sheared at $170{ }^{\circ} \mathrm{C}$ and then cooled to RT at $30^{\circ} \mathrm{C} / \mathrm{min}$, collected in Figure 1, exhibit glass transition with $\mathrm{T}_{\mathrm{g}}$ at approx. $60-61^{\circ} \mathrm{C}$, cold crystallization exotherms and melting endotherms, with peaks at $\mathrm{T}_{\mathrm{cc}}$ close to $100{ }^{\circ} \mathrm{C}$ and $\mathrm{T}_{\mathrm{m}}$ above $170{ }^{\circ} \mathrm{C}$, respectively. In addition, on the thermograms, small pre-melting exotherms are visible, with maxima close to $160^{\circ} \mathrm{C}$, which originated from the recrystallization of the disordered alpha' to the ordered alpha orthorhombic form [8]. During heating at $5{ }^{\circ} \mathrm{C} / \mathrm{min}$, the cold-crystallization occurred in a relatively low temperature range and the crystallization exotherms and the melting endotherms did not overlap, which facilitated integration of the peaks and calculation of enthalpies of the processes. The melting enthalpy, $\Delta \mathrm{H}_{\mathrm{mc}}$, of crystals formed during cooling, before the heating in DSC, was calculated by subtracting the enthalpies of exothermic effects of crystallization and recrystallization, $\Delta \mathrm{H}_{\mathrm{cc}}$ and $\Delta \mathrm{H}_{\mathrm{rc}}$, respectively, from the melting enthalpy, $\Delta \mathrm{H}_{\mathrm{m}}$.

For the control specimens, $\Delta \mathrm{H}_{\mathrm{mc}}$ was small, or even close to zero, indicating that they were amorphous or with low crystallinity. However, $\Delta \mathrm{H}_{\mathrm{mc}}$ of the sheared specimens was markedly larger, proving that crystallinity developed in PLLAs during the post-shearing cooling. The differences between the thermograms in Figure 1 evidence that the effect of shear depended on the molar mass, but also on the macromolecular architecture of PLLAs studied. 


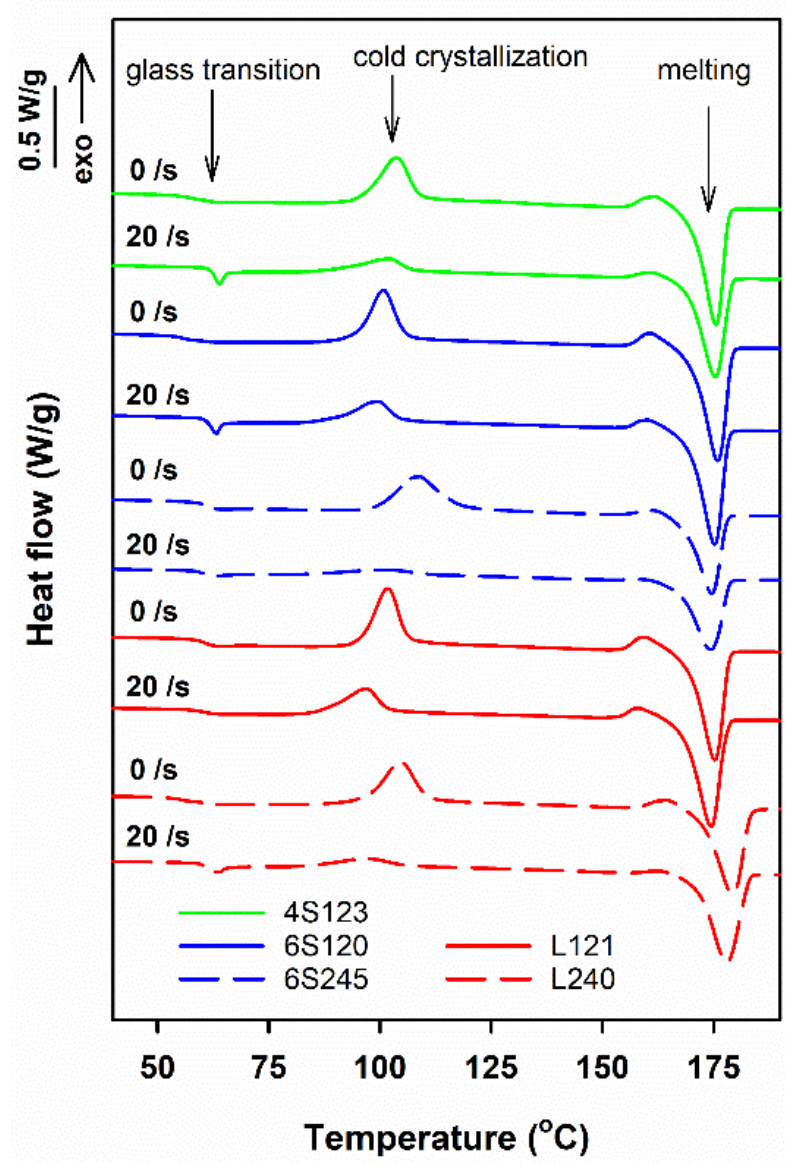

Figure 1. DSC heating thermograms of PLLAs sheared at $20 / \mathrm{s}$ for $5 \mathrm{~s}$ at $150{ }^{\circ} \mathrm{C}$ and next cooled at $30^{\circ} \mathrm{C} / \mathrm{min}$, and thermograms of control specimens cooled at $30^{\circ} \mathrm{C} / \mathrm{min}$. The curves shifted vertically for clarity.

It must be noted that such approach does not take into account the temperature dependence of heat of fusion, due to which $\Delta \mathrm{H}_{\mathrm{cc}}$ of the cold-crystallized crystals can be lower than their melting enthalpy. However, although $\mathrm{T}_{\mathrm{m}}-\mathrm{T}_{\mathrm{cc}}$ was up to about $70{ }^{\circ} \mathrm{C}$, in most cases $\Delta \mathrm{H}_{\mathrm{cc}}$ was significantly smaller than $\Delta \mathrm{H}_{\mathrm{mc}}$, therefore reducing the overestimation of the latter. Another effect that should be considered is the difference in the heat of fusion of the ordered alpha form and the disordered alpha' form of PLLA. It is known that between 100 and $120^{\circ} \mathrm{C}$ PLLA crystallizes not only in the ordered alpha modification but also in the disordered alpha' form. Below $100{ }^{\circ} \mathrm{C}$, PLLA crystallizes from the quiescent melt only in the alpha' form [8], although the alpha form was found after shear-induced crystallization at $96^{\circ} \mathrm{C}$ [44]. Although the heat of fusion of the alpha' crystals is significantly lower than that of the alpha modification [45], the influence of that on $\Delta \mathrm{H}_{\mathrm{mc}}$ can be neglected, because of the alpha' to alpha recrystallization prior to melting. In addition, the alpha' to alpha recrystallization occurring near $160{ }^{\circ} \mathrm{C}$ and also reorganization occurring in the alpha phase prior to melting, further reduce the possible overestimation of $\Delta \mathrm{H}_{\mathrm{mc}}$.

Figure 2 illustrates the effect of shearing conditions and post-shearing cooling on $\Delta \mathrm{H}_{\mathrm{mc}}$ and mass crystallinity, $\chi_{\mathrm{c}}$ of linear and star PLLAs. The $\Delta \mathrm{H}_{\mathrm{mc}}$ values are averages, based on at least two or three measurements. The mass crystallinity, $\chi_{c}$, was calculated from $\Delta \mathrm{H}_{\mathrm{mc}}$, assuming that the heat of fusion of $100 \%$ crystalline PLLA is $106 \mathrm{~J} / \mathrm{g}$ [46]. 


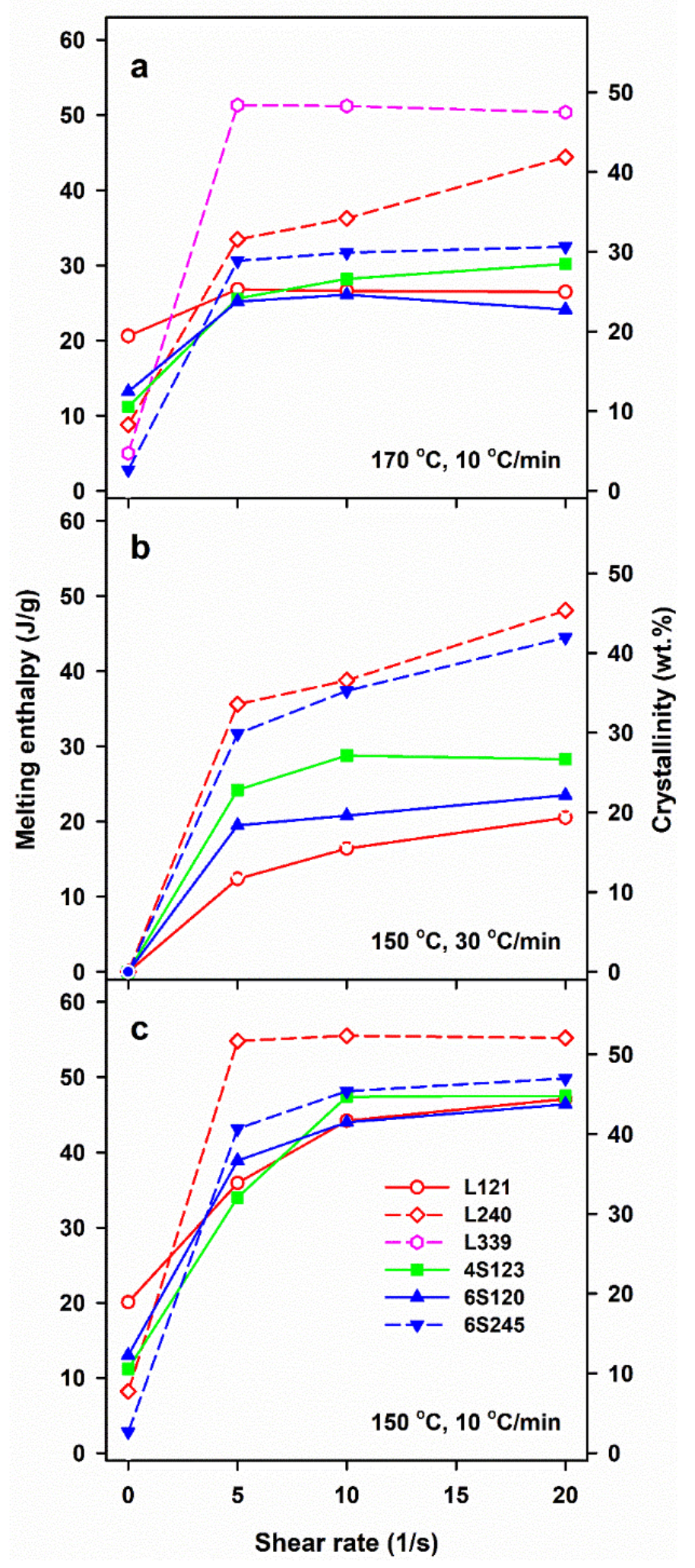

Figure 2. Melting enthalpy, $\Delta \mathrm{H}_{\mathrm{mc}}$, of crystalline phase formed in PLLAs during cooling at 10 and $30^{\circ} \mathrm{C} / \mathrm{min}$ after shearing at $170^{\circ} \mathrm{C}(\mathbf{a})$ and $150^{\circ} \mathrm{C}(\mathbf{b}, \mathbf{c})$ versus shear rate, $\dot{\gamma}$. 
The control specimens cooled at $30^{\circ} \mathrm{C} / \mathrm{min}$ were practically amorphous, whereas in those cooled at $10^{\circ} \mathrm{C} / \mathrm{min}$ crystallization occurred, although $\Delta \mathrm{H}_{\mathrm{mc}}$ and the corresponding $\chi_{c}$ were small, being the largest for L121, close to $20 \mathrm{~J} / \mathrm{g}$ and $19 \%$, respectively, as previously found for the same polymer [24]. Shearing at 150 and $170{ }^{\circ} \mathrm{C}$ enhanced crystallization in all PLLAs. In general, $\Delta \mathrm{H}_{\mathrm{mc}}$ increased with $\dot{\gamma}$, although weakly in most cases, or was even independent of $\dot{\gamma}$, most possibly due to the same final shear strain achieved during all experiments. Moreover, $\Delta \mathrm{H}_{\mathrm{mc}}$ of L339 sheared at $170{ }^{\circ} \mathrm{C}$ and $\mathrm{L} 240$ sheared at $150{ }^{\circ} \mathrm{C}$, and next cooled at $10{ }^{\circ} \mathrm{C} / \mathrm{min}$, reached very high values even for $\dot{\gamma}$ of only $5 / \mathrm{s}$.

Shearing at $170{ }^{\circ} \mathrm{C}$ followed by cooling at $30{ }^{\circ} \mathrm{C} / \mathrm{min}$ resulted in rather low $\Delta \mathrm{H}_{\mathrm{mc}}$ of all PLLAs, up to about $15 \mathrm{~J} / \mathrm{g}$, except L240 and L339, for which $\Delta \mathrm{H}_{\mathrm{mc}}$. values were higher. A decrease of $\mathrm{v}$ to $10{ }^{\circ} \mathrm{C} / \mathrm{min}$ enhanced the post-shearing crystallization in all PLLAs. As seen in Figure $2 \mathrm{a}, \Delta \mathrm{H}_{\mathrm{mc}}$ values of PLLAs with $\mathrm{M}_{\mathrm{w}}$ close to $120 \mathrm{~kg} / \mathrm{mol}$ ranging from 24 to $30 \mathrm{~J} / \mathrm{g}$ were similar. Slightly higher $\Delta \mathrm{H}_{\mathrm{mc}}$ of $31-32 \mathrm{~J} / \mathrm{g}$ was found for $6 \mathrm{~S} 245$, and even higher up to $44 \mathrm{~J} / \mathrm{g}$ for L240. The effect of shear on the crystallization of L339 was the strongest, which was reflected in $\Delta \mathrm{H}_{\mathrm{mc}}$ close to $50 \mathrm{~J} / \mathrm{g}$. A decrease of $\mathrm{T}_{\mathrm{s}}$ to $150{ }^{\circ} \mathrm{C}$ intensified the post-shearing crystallization at both cooling rates. L339 crystallized during shearing at $150{ }^{\circ} \mathrm{C}$; hence, studies of its post-shearing nonisothermal crystallization were impossible. As seen in Figure $2 \mathrm{~b}, \Delta \mathrm{H}_{\mathrm{mc}}$. values of PLLAs with $\mathrm{M}_{\mathrm{w}}$ close to $120 \mathrm{~kg} / \mathrm{mol}$, cooled at $30{ }^{\circ} \mathrm{C} / \mathrm{min}$, increased up to $21-29 \mathrm{~J} / \mathrm{g}$, and those of $6 \mathrm{~S} 245$ and L240 to 44 and $48 \mathrm{~J} / \mathrm{g}$, respectively. Slower cooling, at $10{ }^{\circ} \mathrm{C} / \mathrm{min}$, resulted in higher $\Delta \mathrm{H}_{\mathrm{mc}}$, in the range of 34-47 J/g for PLLAs with $\mathrm{M}_{\mathrm{w}}$ close to $120 \mathrm{~J} / \mathrm{g}$, whereas in the range of $43-49 \mathrm{~J} / \mathrm{g}$ and $55 \mathrm{~J} / \mathrm{g}$ for $6 \mathrm{~S} 245$ and L240, respectively, as s shown in Figure 2c.

DSC measurements allow us to determine only the final $\chi_{c}$ developed during postshearing cooling, whereas the light depolarization method enables us to follow the increase of $\alpha_{\mathrm{vr}}$ during crystallization. To compare the crystallinity increase in specimens with different final crystallinity, volume crystallinity $\alpha_{v}(T)$ equal to $\alpha_{v r}(T) \chi_{v}$, was plotted in Figure 3 , where $\chi_{v}$ is the final volume crystallinity calculated based on $\chi_{c}$ and the densities of the amorphous and crystalline phases of PLA [47]. As it is explained above, $\chi_{c}$ was calculated based on the melting enthalpy of crystals formed during post-shearing cooling, $\Delta \mathrm{H}_{\mathrm{mc}}$. It should be mentioned that the lower melting enthalpy of the alpha' phase was not accounted for because $\Delta \mathrm{H}_{\mathrm{mc}}$ was determined from the melting endotherm preceded by the pre-melting recrystallization of alpha' to alpha form. Differentiation of $\alpha_{v}(T)$ with respect to temperature permitted to obtain the temperature dependencies of crystallization rate. It appears that the lower $T_{S}$, slower cooling and higher $M_{w}$ of PLLA resulted in the higher temperature range of crystallization. The effect of $\dot{\gamma}, \mathrm{T}_{\mathrm{S}}$ and $\mathrm{v}$, as well as of $\mathrm{M}_{\mathrm{w}}$ of PLLA and its macromolecular architecture, on $T_{c}$ was similar to that on $\Delta H_{m c}$, as it is shown in Figure $4 . \mathrm{T}_{\mathrm{c}}$ correlated with $\Delta \mathrm{H}_{\mathrm{mc}}$ and crystallinity, the higher the former the larger the latter. $\mathrm{T}_{\mathrm{C}}$ increased with decreasing $\mathrm{T}_{\mathrm{S}}$ and $\mathrm{v}$, and with increasing $\dot{\gamma}$. The highest $\mathrm{T}_{\mathrm{c}}$ values were found for L339, lower for L240 and 6S245, and even lower for 4S123, 6S120 and L121, showing the influence of $\mathrm{M}_{\mathrm{W}}$, but also of the macromolecular architecture.

The results show a crucial role of $T_{S}$ and $v$. The lower $T_{S}$ increased the relaxation times of macromolecules and lowered the energy barrier for nucleation, thus enhancing the shear-induced crystallization. In turn, the slower cooling enabled a longer time for crystallization before too low temperature was reached, increasing therefore $\mathrm{T}_{\mathrm{c}}, \Delta \mathrm{H}_{\mathrm{mc}}$ and $\chi_{c}$, the latter determined based on $\Delta \mathrm{H}_{\mathrm{mc}}$. However, not only the shearing conditions and $\mathrm{v}$ determined the post-shearing crystallization. $\mathrm{T}_{\mathrm{c}}$ and $\Delta \mathrm{H}_{\mathrm{mc}}$ were strongly influenced by molar masses of PLLAs, as can be expected, but they were also affected by macromolecular architecture. Figure $2 \mathrm{~b}$ shows that in the case of cooling at $30{ }^{\circ} \mathrm{C} / \mathrm{min}$, the shearing at $150{ }^{\circ} \mathrm{C}$ had the weakest effect on L121, stronger on $6 \mathrm{~S} 120$, and the strongest on 4 S123 crystallization. Figure $2 \mathrm{a}, \mathrm{c}$ show that during cooling at $10^{\circ} \mathrm{C} / \mathrm{min} \mathrm{T}_{\mathrm{C}}$ and $\Delta \mathrm{H}_{\mathrm{mc}}$ values of all PLLAs with $\mathrm{M}_{\mathrm{w}}$ near $120 \mathrm{~kg} / \mathrm{mol}$ were similar. However, it must be reminded that in the temperature range of $120-145^{\circ} \mathrm{C}$ the crystal growth rate of L121 was higher than that of the other PLLAs studied [24]. The crystallization kinetics is governed by both the crystal growth rate and the nucleation rate [48], hence, similar $T_{c}$ and $\Delta H_{m c}$ values 
of L121, 6S120 and 4S123 are suggestive of much stronger nucleation in the two latter. The control specimens cooled at $30^{\circ} \mathrm{C} / \mathrm{min}$ were practically amorphous but crystallized during cooling at $10^{\circ} \mathrm{C} / \mathrm{min}$. The shear-induced increase of $\Delta \mathrm{H}_{\mathrm{mc}}$ and $\mathrm{T}_{\mathrm{c}}$ of specimens cooled at $10^{\circ} \mathrm{C} / \mathrm{min}$ is plotted in Figure 5 and Figure S1 in Supplementary Information (SI), respectively. The plots clearly show that the shear enhanced more the crystallization of $4 \mathrm{~S} 123$ and $6 \mathrm{~S} 120$ than that of L121, despite the higher $\mathrm{M}_{\mathrm{z}}$ of the latter.

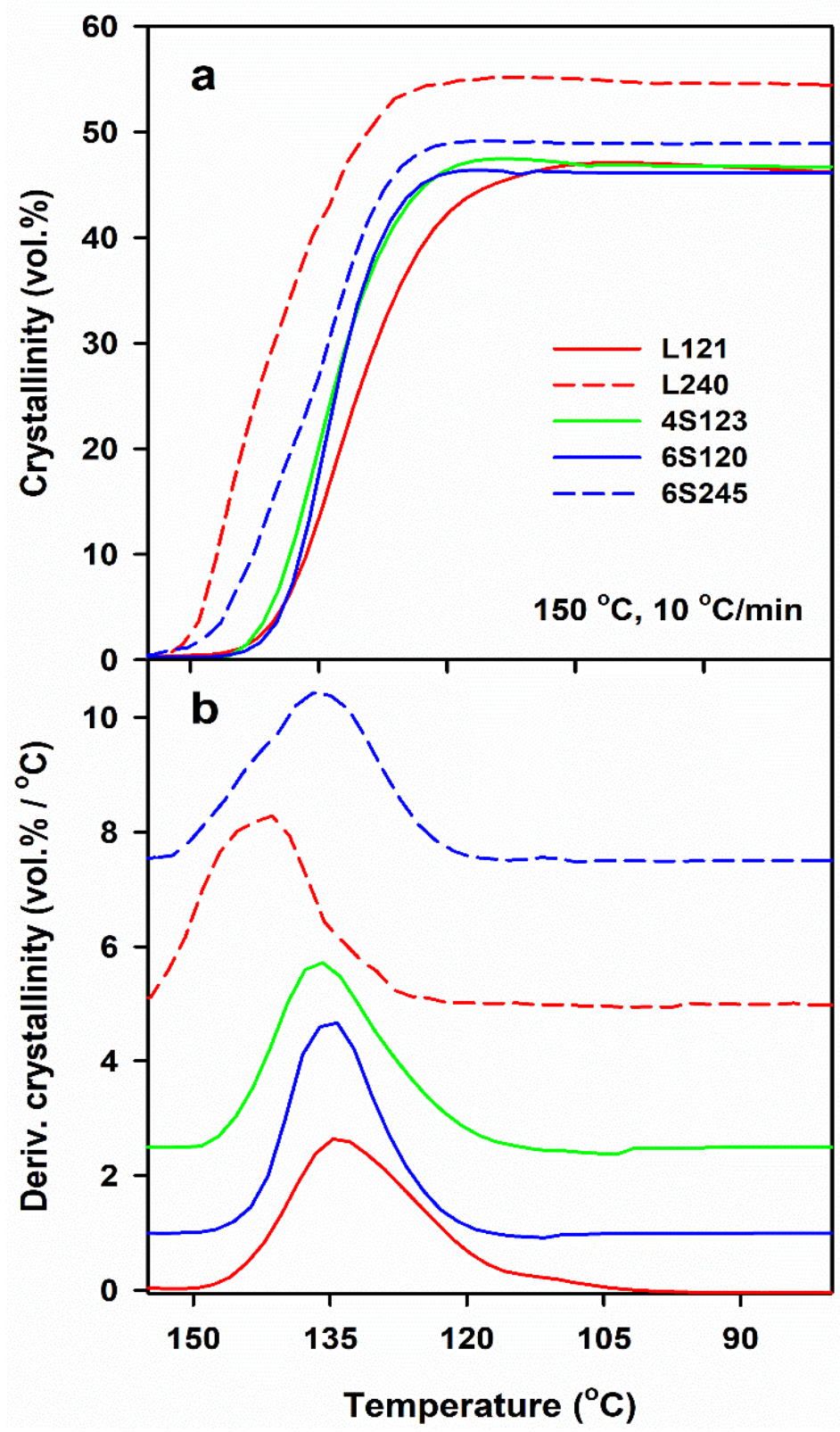

Figure 3. Development of crystallinity determined by light depolarization method (a) and derivative of crystallinity with respect to temperature (b) in PLLAs during cooling at $10^{\circ} \mathrm{C} / \mathrm{min}$ after shearing at $20 / \mathrm{s}, 150{ }^{\circ} \mathrm{C}$. The curves in Figure $3 \mathrm{~b}$ shifted vertically for clarity. 


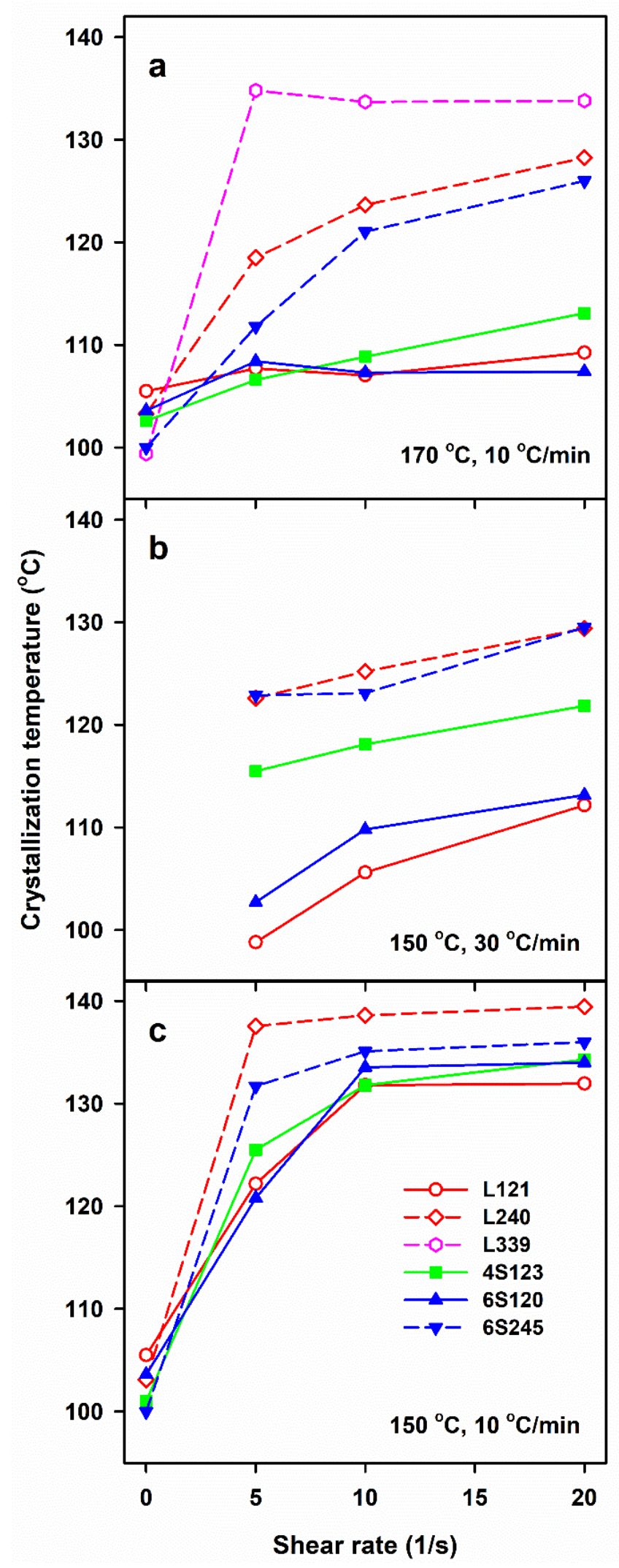

Figure 4. Crystallization peak temperature, $\mathrm{T}_{\mathrm{c}}$, during cooling of PLLAs at 10 and $30^{\circ} \mathrm{C} / \mathrm{min}$ after shearing at $170{ }^{\circ} \mathrm{C}(\mathbf{a})$ and $150{ }^{\circ} \mathrm{C}(\mathbf{b}, \mathbf{c})$ versus shear rate, $\dot{\gamma}$. 


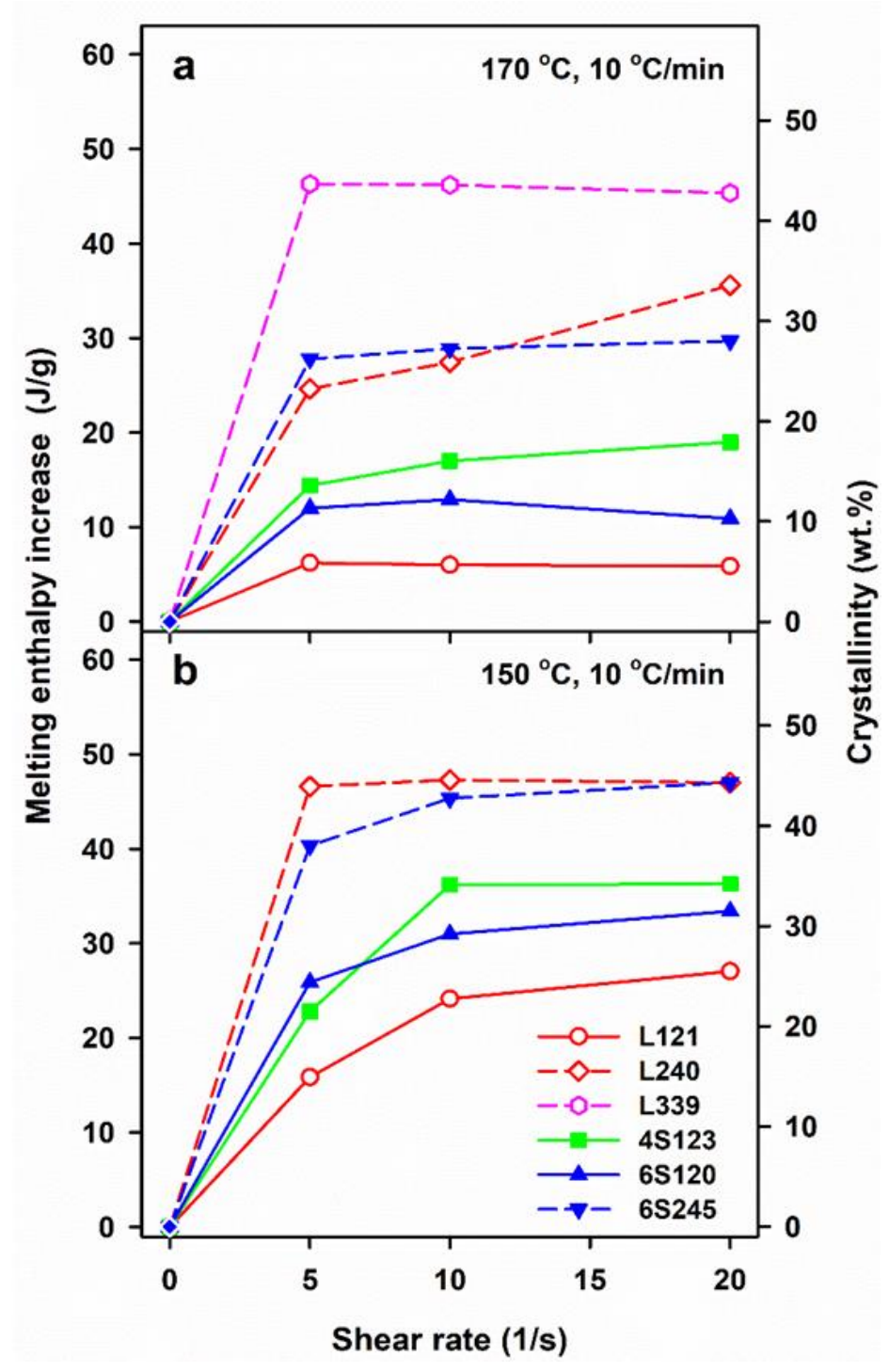

Figure 5. Increase of melting enthalpy, $\Delta \mathrm{H}_{\mathrm{mc}}-\Delta \mathrm{H}_{\mathrm{mc}} \mathrm{q}$, of crystalline phase formed in PLLAs during cooling at $10{ }^{\circ} \mathrm{C} / \mathrm{min}$ caused by shearing at $170{ }^{\circ} \mathrm{C}(\mathbf{a})$ and $150{ }^{\circ} \mathrm{C}(\mathbf{b})$ versus shear rate, $\dot{\gamma} \cdot \Delta \mathrm{H}_{\mathrm{mc}} \mathrm{q}$ denotes the melting enthalpy of crystals formed during cooling at $10^{\circ} \mathrm{C} / \mathrm{min}$ in control specimens.

The enhancement of the effect of shear in 6 S120 and 4 S123 as compared to L121 was undoubtedly caused by the star architecture of macromolecules, which hindered the relaxation of the stretched macromolecular chain network. In contrast to that, the shearinduced crystallization in 6S245 and L240, was similar, and even stronger in the latter, as shown in Figures 2 and 5. Although 6S245 and L240 had similar $M_{n}$ and $M_{w}, M_{z}$ of L240, $414 \mathrm{~kg} / \mathrm{mol}$, exceeded that of $6 \mathrm{~S} 245,294 \mathrm{~kg} / \mathrm{mol}$, evidencing the higher content of larger macromolecules, which presence compensated the effect of 6S245 star architecture on the shear-induced crystallization. In the flow-induced crystallization of a polymer a high molar mass tail of its molar mass distribution plays a crucial role, due to long relaxation times, and at $\mathrm{M}_{\mathrm{W}}$ of $240-245 \mathrm{~kg} / \mathrm{mol}$ its effect compensated that of star architecture. It is also of importance that due to its higher molar mass, the number of branching points in 6S245 was smaller than in 6S120, hence their effect on the macromolecular mobility was reduced.

The crystallization, which was not completed during cooling continued during subsequent heating in DSC, resulting in cold-crystallization exotherms with peaks at $\mathrm{T}_{\mathrm{cc}}$ of 97-109 ${ }^{\circ} \mathrm{C}$, as shown in Figure 1. In many cases, pre-melting exotherms, with maxima at 159-164 ${ }^{\circ} \mathrm{C}$, evidenced the alpha' to alpha form recrystallization. Usually, single melting 
peaks were observed, with $\mathrm{T}_{\mathrm{m}}$ of $174-179{ }^{\circ} \mathrm{C}$, although some of them with shoulders. As shown in Figure 6, $\Delta \mathrm{H}_{\mathrm{m}}$ values of the control specimens of $6 \mathrm{~S} 245$ were equal to $37-38 \mathrm{~J} / \mathrm{g}$, whereas those of the other control PLLAs studied were higher, ranging from 43 to $51 \mathrm{~J} / \mathrm{g}$. The sheared PLLAs exhibited increased $\Delta \mathrm{H}_{\mathrm{m}}$ of 39-55 J/g. The lowest values of $\Delta \mathrm{H}_{\mathrm{m}}$ were those of $6 \mathrm{~S} 245$ cooled at $10{ }^{\circ} \mathrm{C} / \mathrm{min}$ after shearing at $170{ }^{\circ} \mathrm{C}$, and cooled at $30^{\circ} \mathrm{C} / \mathrm{min}$ after shearing at $150^{\circ} \mathrm{C}$, as seen in Figure 6. In turn, among PLLAs sheared at $150^{\circ} \mathrm{C}$ and cooled at $10^{\circ} \mathrm{C} / \mathrm{min}$, L240 exhibited the highest $\Delta \mathrm{H}_{\mathrm{m}}$, as evidenced in Figure $6 \mathrm{c}$. These differences reflect the different ability of PLLAs studied to crystallize, as described in [24], and the different effect of shear influenced by the molar masses and macromolecular architecture of the studied PLLAs.

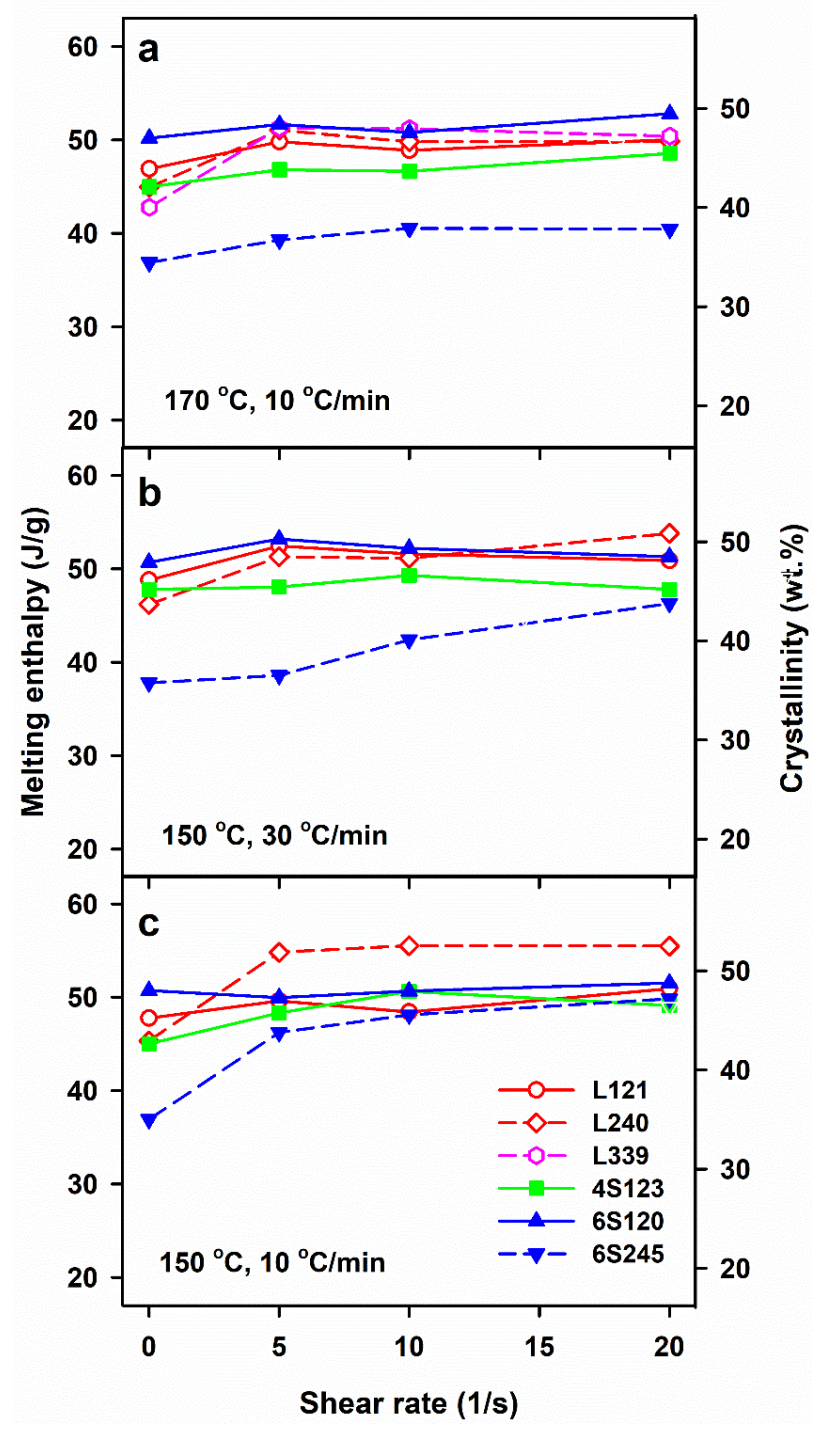

Figure 6. Melting enthalpy, $\Delta \mathrm{H}_{\mathrm{m}}$, measured during DSC heating at $5^{\circ} \mathrm{C} / \mathrm{min}$ of PLLAs previously cooled at 10 and $30^{\circ} \mathrm{C} / \mathrm{min}$, after shearing at $170{ }^{\circ} \mathrm{C}(\mathbf{a})$ and $150^{\circ} \mathrm{C}(\mathbf{b}, \mathbf{c})$ versus shear rate, $\dot{\gamma}$.

\subsection{Structure}

Examples of 2D-WAXS and 2D-SAXS patterns of sheared PLLA specimens are collected in Figures 7 and 8. Generally, the intensities of the reflections from the crystalline phase correlated with $\chi_{\mathcal{C}}$ determined from DSC thermograms and plotted in Figure 2, and increased with increasing $\chi_{c}$. (200)/(110) and (203) reflections (indicated by arrows in Figure S2 in SI) typical of both alpha and alpha' modifications were well visible on all 
patterns. Also, (210) reflection near $2 \theta$ of $22^{\circ}$ characteristic of the alpha form was present in all the patterns, evidencing that the alpha phase was formed in all sheared specimens.

a

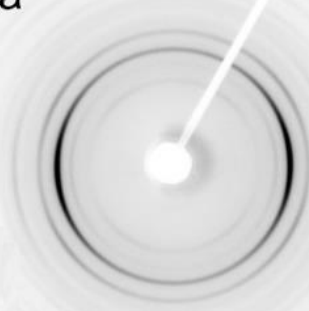

C

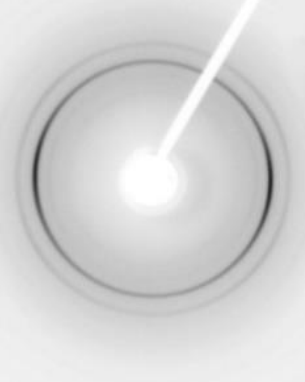

e

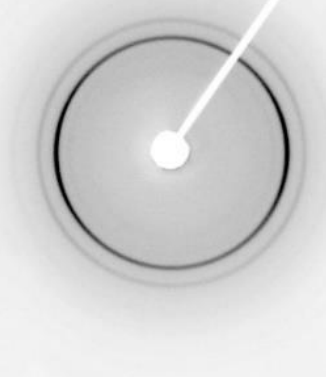

9

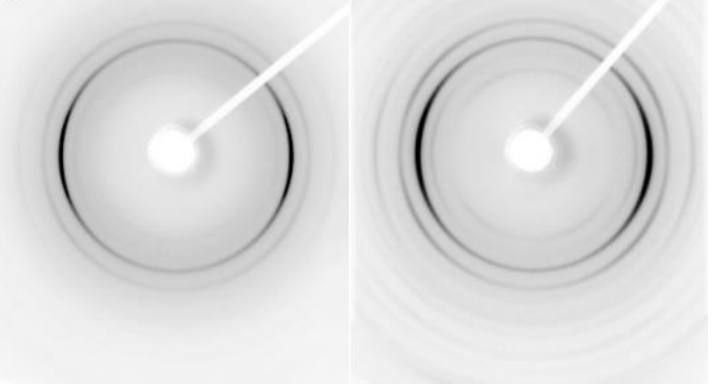

b

d

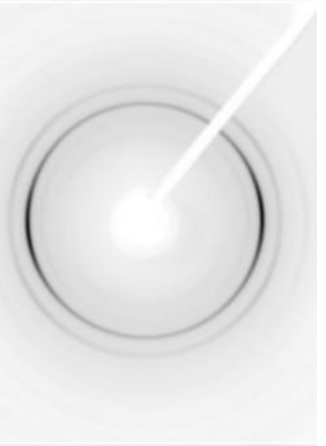

$f$

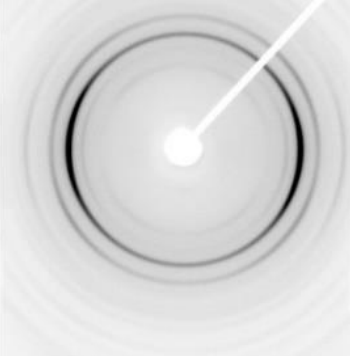

$\mathrm{h}$

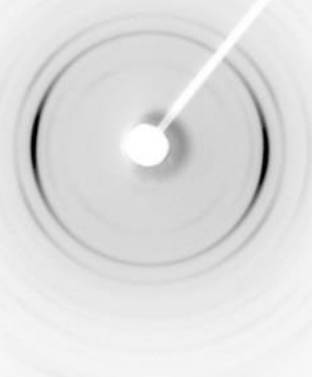

(1)
7. 2D-WAXS patterns of PLLAs: L339 sheared at $170{ }^{\circ} \mathrm{C}$ at $5 / \mathrm{s}$ for $20 \mathrm{~s}$ (a) and at $20 / \mathrm{s}$ for $5 \mathrm{~s}$ (b) and cooled at $10^{\circ} \mathrm{C} / \mathrm{min}, 4 \mathrm{~S} 123$ sheared at $150{ }^{\circ} \mathrm{C}$ at $10 / \mathrm{s}$ for $10 \mathrm{~s} \mathrm{(c)} \mathrm{and} \mathrm{at} 20 / \mathrm{s}$ for $5 \mathrm{~s}$ (d) cooled at $30^{\circ} \mathrm{C} / \mathrm{min}, \mathrm{L} 240$ sheared at $150{ }^{\circ} \mathrm{C}$ at $10 / \mathrm{s}$ for $10 \mathrm{~s}(\mathbf{e})$ and at $20 / \mathrm{s}$ for $5 \mathrm{~s} \mathrm{(f)} \mathrm{cooled} \mathrm{at} 30^{\circ} \mathrm{C} / \mathrm{min}$, 6 S245 sheared at $150{ }^{\circ} \mathrm{C}$ at $10 / \mathrm{s}$ for $10 \mathrm{~s} \mathrm{(g)}$ and at $20 / \mathrm{s}$ for $5 \mathrm{~s} \mathrm{(h)} \mathrm{cooled} \mathrm{at} 30^{\circ} \mathrm{C} / \mathrm{min}$. Shearing direction -vertical. 


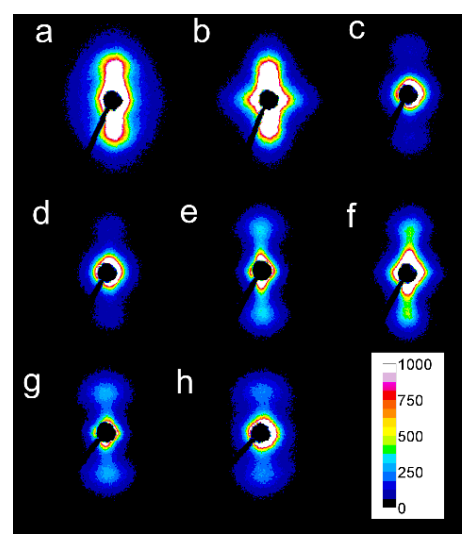

Figure 8. 2D-SAXS patterns of PLLAs: L339 sheared at $170{ }^{\circ} \mathrm{C}$ at $5 / \mathrm{s}$ for $20 \mathrm{~s} \mathrm{(a)}$ and at $20 / \mathrm{s}$ for $5 \mathrm{~s}$ (b) and cooled at $10{ }^{\circ} \mathrm{C} / \mathrm{min}, 4 \mathrm{~S} 123$ sheared at $150{ }^{\circ} \mathrm{C}$ at $10 / \mathrm{s}$ for $10 \mathrm{~s} \mathrm{(c)} \mathrm{and} \mathrm{at} 20 / \mathrm{s}$ for $5 \mathrm{~s}$ (d) cooled at $30{ }^{\circ} \mathrm{C} / \mathrm{min}$, L240 sheared at $150{ }^{\circ} \mathrm{C}$ at $10 / \mathrm{s}$ for $10 \mathrm{~s}(\mathbf{e})$ and at $20 / \mathrm{s}$ for $5 \mathrm{~s}(\mathbf{f})$ cooled at $30^{\circ} \mathrm{C} / \mathrm{min}$, 6 S245 sheared at $150{ }^{\circ} \mathrm{C}$ at $10 / \mathrm{s}$ for $10 \mathrm{~s}(\mathrm{~g})$ and at $20 / \mathrm{s}$ for $5 \mathrm{~s} \mathrm{(h)} \mathrm{cooled} \mathrm{at} 30^{\circ} \mathrm{C} / \mathrm{min}$. Shearing direction-vertical.

This is in accordance with the $T_{c}$ values shown in Figure 4, which indicate that the crystallization of most of the specimens occurred fully or partially above $110^{\circ} \mathrm{C}$; the higher the $T_{c}$ the more intense was the (210) reflection. Only very weak (210) reflections were discernible in the patterns of PLLAs (not shown), which $\mathrm{T}_{\mathrm{c}}$ was close to $100^{\circ} \mathrm{C}$, for instance, L121 and $6 \mathrm{~S} 120$ sheared at $150{ }^{\circ} \mathrm{C}$ at $5 / \mathrm{s}$ and cooled at $30^{\circ} \mathrm{C} / \mathrm{min}$, which indicated small alpha content.

In some of the 2D-WAXS patterns, intensities of (200)/(110) and (210) reflections were enhanced in equatorial regions, indicating the orientation of the respective crystallographic planes parallel to the shearing direction, and thus evidencing the orientation of polymer chain axes in the flow direction. This was corroborated by the strong polar reflections in the corresponding 2D-SAXS patterns reflecting the orientation of lamellae stacks perpendicular to the flow direction.

Among the specimens sheared at $170^{\circ} \mathrm{C}$ and next cooled at $10^{\circ} \mathrm{C} / \mathrm{min}$, L339 clearly exhibited such orientation, as shown in Figure 7a,b, and in Figure 8a,b. Weaker orientation was also detected in $6 \mathrm{~S} 245$ and L240 sheared at 20/s (not shown). Shearing at $150{ }^{\circ} \mathrm{C}$ followed by cooling at $30^{\circ} \mathrm{C} / \mathrm{min}$ resulted in the crystal orientation in L240, 6S245, and $4 \mathrm{~S} 123$ evidenced in Figures $7 \mathrm{c}-\mathrm{g}$ and $8 \mathrm{c}-\mathrm{g}$. The orientation, although weaker, was also reflected in the patterns of L121 sheared at 20/s, 6S120 sheared at 10/s and 20/s (not shown). 2D-WAXS and 2D-SAXS patterns of PLLAs sheared at $150{ }^{\circ} \mathrm{C}$ and next cooled at $10{ }^{\circ} \mathrm{C} / \mathrm{min}$ evidenced the same features of the morphology. It is well visible in 2DSAXS patterns collected in Figure $9 \mathrm{a}-\mathrm{e}$, in which scattering from the crystalline phase was enhanced due to the higher $\chi_{c}$ developed during slower cooling.

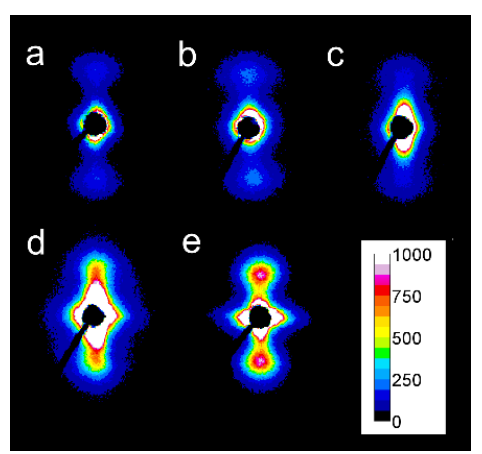

Figure 9. 2D-SAXS patterns of PLLAs: sheared at $150{ }^{\circ} \mathrm{C}$ at $20 / \mathrm{s}$ for $5 \mathrm{~s}$ and cooled at $10{ }^{\circ} \mathrm{C} / \mathrm{min}$ : L121 (a), 4S123 (b), 6S120 (c), L240 (d), 6S245 (e). Shearing direction-vertical. 
The reason for the orientation of crystals was the shear-induced formation of fibrillar nuclei aligned in the shearing direction on which grew lamella stacks perpendicular to the shearing direction. This is well seen in SEM micrographs of cross-section surfaces of sheared PLLAs, presented in Figure 10. The micrograph of L339 sheared at $170{ }^{\circ} \mathrm{C}$ at $20 / \mathrm{s}$ and next cooled at $10^{\circ} \mathrm{C} / \mathrm{min}$, in Figure 9a, evidences the presence of lamellar stacks perpendicular or nearly perpendicular to the shearing direction, and lamella fans developed from the stacks. The stacks form cylindrical structures suggestive of nucleation on fibrillar nuclei. Similar morphology was found in L240 sheared at $150{ }^{\circ} \mathrm{C}$ at $20 / \mathrm{s}$, and next cooled at $30^{\circ} \mathrm{C} / \mathrm{min}$, as shown in Figure $10 \mathrm{~b}$, although spherulites between cylindrical structures were also discernible. Figure 10c presents $6 S 245$ sheared at the same conditions and cooled at the same rate. In the micrograph, cylindrical structures are seen accompanied by spherulites, with radii of several micrometers. Amorphous areas are visible in few places between the spherulites, where crystallization was not accomplished. In L121, 6S120 and $4 \mathrm{~S} 123$ sheared at $150{ }^{\circ} \mathrm{C}$ at $20 / \mathrm{s}$ crystallization during cooling at $30^{\circ} \mathrm{C} / \mathrm{min}$ was even less advanced, as shown in Figure 10d-f. The cylindrical structures and spherulites between them are well distinguishable, the latter more numerous than in PLLAs with higher $M_{w}$. The effect of slower cooling on PLLAs sheared at $150{ }^{\circ} \mathrm{C}$ at $20 / \mathrm{s}$ is illustrated in Figure 11. The morphology of L240 and $6 \mathrm{~S} 245$ cooled at $10{ }^{\circ} \mathrm{C} / \mathrm{min}$ was similar to that observed after faster cooing, as exemplified in Figure 11a showing L240. In PLLAs with $\mathrm{M}_{\mathrm{w}}$ close to $120 \mathrm{~kg} / \mathrm{mol}$ amorphous areas were not visible any longer because of high $\chi_{\mathrm{c}}$ reached in these polymers during slower cooling. The specimens were completely filled with cylindrical structures and spherulites between them, as seen in Figure 11b showing L121.
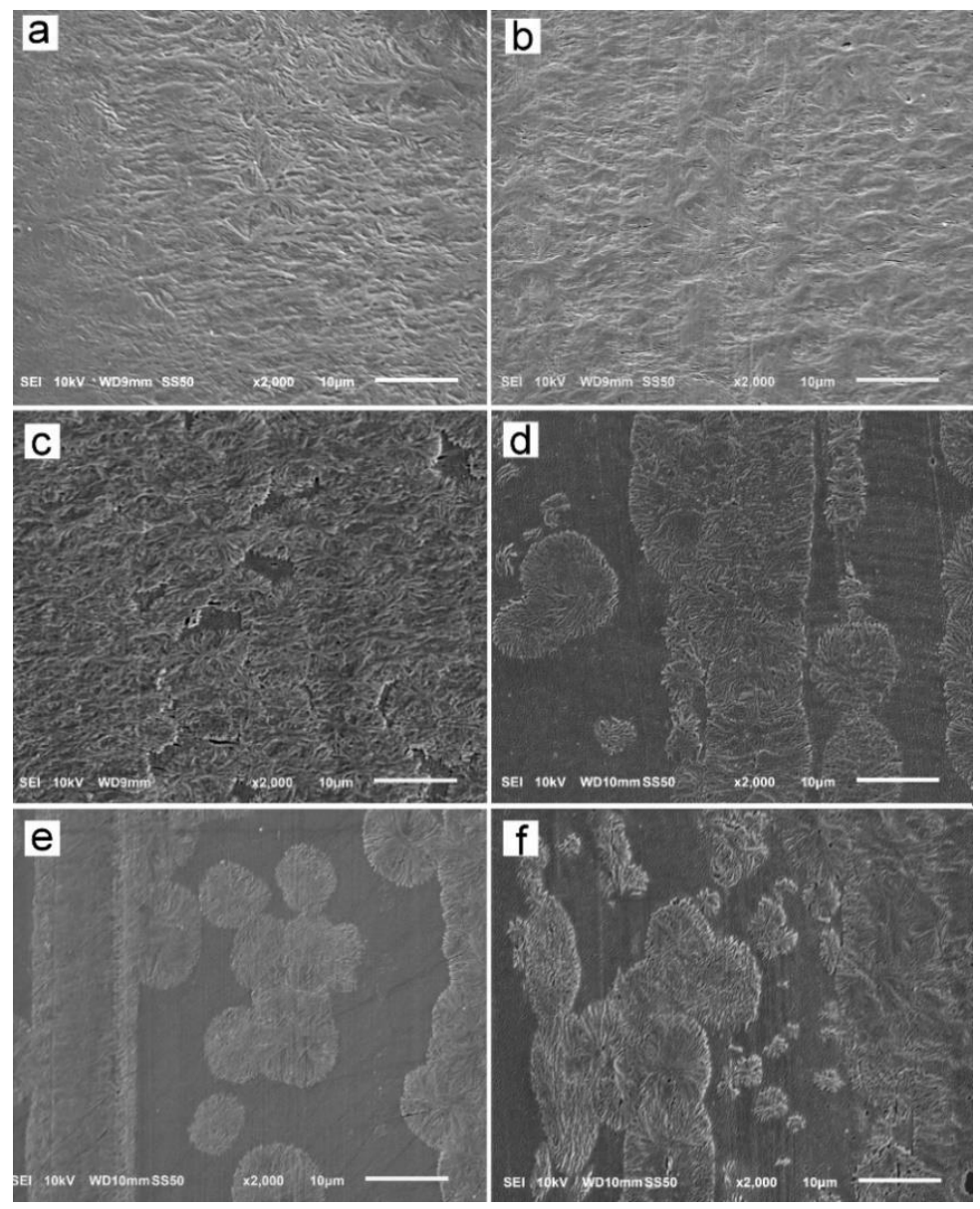

Figure 10. SEM micrographs of etched cross-section surfaces of PLLAs: L339 sheared at $170{ }^{\circ} \mathrm{C}$ at 5/s for $20 \mathrm{~s}$, and next cooled at $10^{\circ} \mathrm{C} / \mathrm{min}(\mathbf{a})$, and L240 (b) 6S245 (c), L121 (d), 4S123 (e), $6 \mathrm{~S} 120$ (f) sheared at $150{ }^{\circ} \mathrm{C}$ at $20 / \mathrm{s}$ for $5 \mathrm{~s}$, and next cooled at $30^{\circ} \mathrm{C} / \mathrm{min}$. Shearing direction-vertical. 


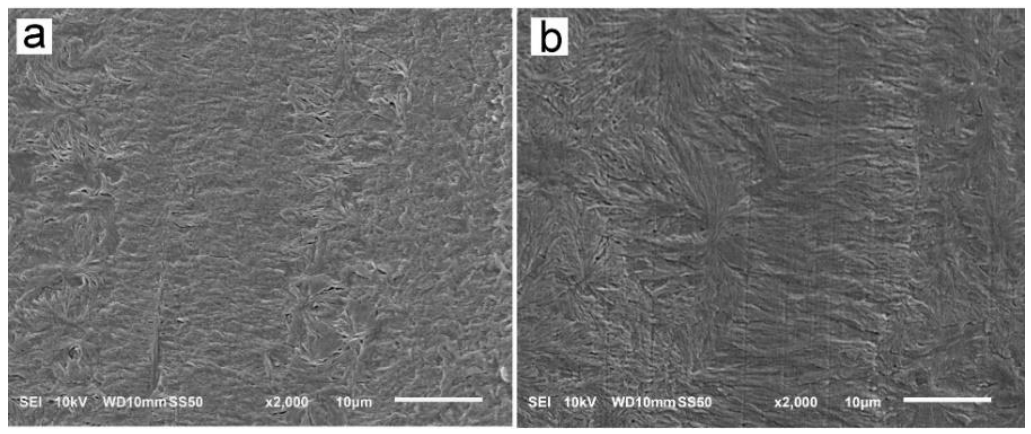

Figure 11. SEM micrographs of etched cross-section surfaces of L240 (a) and L121(b) sheared at $150{ }^{\circ} \mathrm{C}$ at $20 / \mathrm{s}$ for $5 \mathrm{~s}$, and next cooled at $10^{\circ} \mathrm{C} / \mathrm{min}$. Shearing direction-vertical.

2D-WAXS results evidenced orientation of the orthorhombic crystals of PLLAs with (200)/(110) and (210) crystallographic planes parallel to the shearing direction; hence, the orientation of polymer chain axes in the flow direction. It was accompanied by strong polar reflections in the corresponding 2D-SAXS patterns reflecting the orientation of lamellae stacks perpendicular to the flow direction. The orientation of crystals was stronger in PLLAs with $\mathrm{M}_{\mathrm{w}}$ above $200 \mathrm{~kg} / \mathrm{mol}$ than in those with $\mathrm{M}_{\mathrm{w}}$ close to $120 \mathrm{~kg} / \mathrm{mol}$. However, among the latter, $4 \mathrm{~S} 123$ exhibited the strongest orientation, whereas that of L121 was the weakest.

SEM analysis demonstrated the presence of lamellae stacks perpendicular to the shearing direction forming cylindrical structures, nucleated on fibrillar nuclei. These structures were accompanied by spherulites, especially in PLLAs with $\mathrm{M}_{\mathrm{w}}$ close to $120 \mathrm{~kg} / \mathrm{mol}$. Obviously, the shear-induced fibrillar nucleation, although occurred, was less intense in these polymers than in PLLAs with higher $\mathrm{M}_{\mathrm{w}}$, which corroborated the conclusions drawn based on the results of $\mathrm{X}$-ray scattering experiments.

In general, the strongest orientation of crystals was observed for the specimens, which crystallized at the highest temperatures and reached the highest $\chi_{c}$. The crystal orientation resulted from the crystal growth on the shear-induced fibrillar nuclei; the more intense the nucleation, the higher $T_{c}$ and $\chi_{c}$. On the contrary, the weak or absent crystal orientation indicated the predominant point-like nucleation.

\section{Conclusions}

Three star PLLAs, 6-arm with $\mathrm{M}_{\mathrm{w}}$ of 120 and $245 \mathrm{~kg} / \mathrm{mol}$, 4 -arm with $\mathrm{M}_{\mathrm{w}}$ of $123 \mathrm{~kg} / \mathrm{mol}$, and three linear PLLAs with $\mathrm{M}_{\mathrm{W}}$ of 121, 240 and $339 \mathrm{~kg} / \mathrm{mol}$, were synthesized and their shear-induced crystallization was examined. The polymers were sheared at $170{ }^{\circ} \mathrm{C}$ and $150{ }^{\circ} \mathrm{C}$ at $5 / \mathrm{s}, 10 / \mathrm{s}$ and $20 / \mathrm{s}$ for $20 \mathrm{~s}, 10 \mathrm{~s}$, and $5 \mathrm{~s}$, respectively, and next cooled at 10 or $30^{\circ} \mathrm{C} / \mathrm{min}$. The shear flow induced crystallization of the PLLAs during cooling at $30{ }^{\circ} \mathrm{C} / \mathrm{min}$ and enhanced the crystallization at $10{ }^{\circ} \mathrm{C} / \mathrm{min}$, which was reflected in an increase of crystallization peak temperature, $\mathrm{T}_{\mathrm{C}}$, and crystallinity, $\chi_{\mathrm{c}}$. The flow-induced orientation of crystals was evidenced by 2D-WAXS and 2D-SAXS, although dependent on shearing conditions and molecular characteristics of the polymers. The lamellae stack perpendicular to the flow direction, suggestive of fibrillar nucleation, were observed by SEM, although spherulites were found between them, especially in PLLAs with $\mathrm{M}_{\mathrm{w}}$ close to $120 \mathrm{~kg} / \mathrm{mol}$.

The results showed the crucial role of shearing temperature, $\mathrm{T}_{\mathrm{s}}$, and cooling rate, $\mathrm{v}$, as the lower $T_{s}$ increases the relaxation times of macromolecules and loweres the energy barrier for nucleation, whereas the slower cooling enabled a longer time for crystallization before too low temperature was reached. The shear-induced crystallization was also strongly influenced by molar mass of PLLA, as can be expected, but it was also affected by macromolecular architecture. It was well reflected in $\chi_{c}$ of PLLAs with $\mathrm{M}_{\mathrm{w}}$ close to $120 \mathrm{~kg} / \mathrm{mol}$ sheared at $150^{\circ} \mathrm{C}$ and cooled at $30^{\circ} \mathrm{C} / \mathrm{min}$. The effect of shear was the weakest on L121, stronger on $6 \mathrm{~S} 120$, and the strongest on $4 \mathrm{~S} 123$,despite the higher $\mathrm{M}_{\mathrm{Z}}$ of L121. 
During cooling at $10{ }^{\circ} \mathrm{C} / \mathrm{min}, \mathrm{T}_{\mathrm{C}}$ and $\Delta \mathrm{H}_{\mathrm{mc}}$ values of all PLLAs with $\mathrm{M}_{\mathrm{W}}$ near $120 \mathrm{~kg} / \mathrm{mol}$ were similar. However, this evidenced the stronger shear-induced nucleation in both star PLLAs than in L121, because the crystal growth in them was slower than in L121 [24]. The effect of molecular architecture on shear-induced crystallization during cooling at $10{ }^{\circ} \mathrm{C} / \mathrm{min}$ was clearly seen in an increase of $\mathrm{T}_{\mathrm{C}}$ and $\Delta \mathrm{H}_{\mathrm{mc}}$ in respect to the corresponding values for the control specimens, with similar thermal history but not subjected to shearing. The stronger effect of shear on 6S120 and 4S123 as compared to that on L121 undoubtedly resulted from the star architecture of macromolecules, which hindered the relaxation of the stretched macromolecular chain network. On the contrary, the shear-induced crystallization in 6S245 and L240 was similar, and even somewhat stronger in the latter. This can be understood taking into account that in the flow-induced crystallization of polymers, a high molar mass tail of molar mass distribution plays a crucial role, due to long relaxation times. $\mathrm{M}_{\mathrm{Z}}$ of $\mathrm{L} 240,414 \mathrm{~kg} / \mathrm{mol}$, exceeded that of $6 S 245,294 \mathrm{~kg} / \mathrm{mol}$, evidencing the higher content of larger macromolecules, which at $\mathrm{M}_{\mathrm{W}}$ of $240-245 \mathrm{~kg} / \mathrm{mol}$ compensated the effect of star architecture on the shear-induced crystallization. Moreover, due to its higher molar mass, the number of branching points in 6S245 was smaller than in 6S120, which reduced their effect on macromolecular mobility.

Supplementary Materials: The following are available online. Figure S1: Increase of crystallization peak temperature, $\mathrm{T}_{\mathrm{C}}-\mathrm{T}_{\mathrm{C}} \mathrm{q}$, of PLLAs during cooling at $10{ }^{\circ} \mathrm{C} / \mathrm{min}$, caused by shearing at 170 and $150{ }^{\circ} \mathrm{C}$, versus shear rate, $\dot{\gamma} . \mathrm{T}_{\mathrm{C}} \mathrm{q}$ denotes the crystallization peak temperature of control specimens during cooling at $10^{\circ} \mathrm{C} / \mathrm{min}$. Figure S2, 2D-WAXS pattern of PLLA L339 sheared at $170{ }^{\circ} \mathrm{C}$ at $5 / \mathrm{s}$ for $20 \mathrm{~s}$ and next cooled at $10{ }^{\circ} \mathrm{C} / \mathrm{min}$, with arrows indicating characteristic reflections.

Author Contributions: Conceptualization, J.B. and E.P.; methodology, J.B., A.M.; validation, J.B., E.P. and G.L.; formal analysis, J.B.; investigation, J.B.; writing—original draft preparation, J.B., E.P.; writing-review and editing, J.B., E.P.; visualization, J.B.; supervision, E.P.; funding acquisition, G.L. All authors have read and agreed to the published version of the manuscript.

Funding: This research was supported by the National Science Centre (Narodowe Centrum Nauki), Poland, grant No. 2013/09/B/ST5/03619, and statutory funds of CMMS PAS.

Institutional Review Board Statement: Not applicable.

Informed Consent Statement: Not applicable.

Data Availability Statement: The data presented in this study are available on request from the corresponding author.

Acknowledgments: The work was supported by the National Science Centre (Narodowe Centrum Nauki), Poland, grant No. 2013/09/B/ST5/03619 and statutory funds of CMMS PAS.

Conflicts of Interest: The authors declare no conflict of interest.

Sample Availability: Samples of the compounds are not available from the authors.

\section{References}

1. Piorkowska, E. Overview of biobased polymers. Adv. Polym. Sci. 2019, 283, 1-35. [CrossRef]

2. Masutani, K.; Kimura, Y. Present situation and future perspectives of poly(lactic acid). Adv. Polym. Sci. 2017, 279, 1-25. [CrossRef]

3. Babu, R.P.; O'Connor, K.; Seeram, R. Current progress on bio-based polymers and their future trends. Prog. Biomater. 2013, 2, 8. [CrossRef]

4. Castro-Aguirre, E.; Inigues-Franco, F.; Samsudin, H.; Fang, X.; Auras, R. Poly(lactic acid)-mass production, processing, industrial applications, and end of life. Adv. Drug. Deliv. Rev. 2016, 107, 333-366. [CrossRef]

5. Kost, B.; Svyntkivska, M.; Brzeziński, M.; Makowski, T.; Piorkowska, E.; Rajkowska, K.; Kunicka-Styczyńska, A.; Biela, T. $\mathrm{PLA} / \beta-\mathrm{CD}$-based fibres loaded with quercetin as potential antibacterial dressing materials. Colloids Surf. B Biointerfaces 2020, 190, 110949. [CrossRef]

6. Saeidlou, S.; Huneault, M.A.; Li, H.; Park, C.B. Poly(lactic acid) crystallization. Prog. Polym. Sci. 2012, 37, 1657-1677. [CrossRef]

7. Muller, A.J.; Avila, M.; Saenz, G.; Salazar, J. Crystallization of PLA-based materials. In Poly(Lactic Acid) Science and Technology: Processing, Properties, Additives and Applications; Jimenez, A., Peltzer, M., Ruseckaite, R., Eds.; Royal Society of Chemistry: Cambridge, UK, 2015; pp. 66-98. [CrossRef] 
8. Zhang, J.; Tashiro, K.; Tsuji, H.; Domb, A.J. Disorder-to-order phase transition and multiple melting behavior of poly(L-lactide) Investigated by simultaneous measurements of WAXD and DSC. Macromolecules 2008, 41, 1352-1357. [CrossRef]

9. Kalish, J.P.; Aou, K.; Yang, X.; Hsu, S.H. Spectroscopic and thermal analyses of $\alpha^{\prime}$ and $\alpha$ crystalline forms of poly(L-lactic acid). Polymer 2011, 52, 814-821. [CrossRef]

10. Pan, P.; Yang, J.; Shan, G.; Bao, Y.; Weng, Z.; Cao, A.; Yazawa, K.; Inoue, Y. Temperature-variable FTIR and solid-state ${ }^{13}$ C NMR investigations on crystalline structure and molecular dynamics of polymorphic poly(L-lactide) and poly(L-lactide)/poly(D-lactide) stereocomplex. Macromolecules 2012, 45, 189-197. [CrossRef]

11. Michalski, A.; Brzezinski, M.; Lapienis, G.; Biela, T. Star-shaped and branched polylactides: Synthesis, characterization, and properties. Prog. Polym. Sci. 2019, 89, 159-212. [CrossRef]

12. Cameron, D.J.A.; Shaver, M.P. Aliphatic polyester polymer stars: Synthesis, properties and applications in biomedicine and nanotechnology. Chem. Soc. Rev. 2011, 40, 1761-1776. [CrossRef] [PubMed]

13. Srisa-ard, M.; Baimark, Y. Effect of arm number and arm length on thermal properties of linear and star-shaped poly(D,L-lactides)s. J. Appl. Sci. 2010, 10, 1937-1943. [CrossRef]

14. Kim, S.H.; Han, Y.K.; Kim, Y.H.; Hong, S.I. Multifunctional initiation of lactide polymerization by stannous octoate/pentaerythritol. Makromol. Chem. 1992, 193, 1323-1631. [CrossRef]

15. Zhang, W.; Zheng, S. Synthesis and characterization of dendritic star poly(L-lactide)s. Polym. Bull. 2007, 58, 767-775. [CrossRef]

16. Zhang, C.X.; Wang, B.; Chen, Y.; Cheng, F.; Jiang, S.C. Amphiphilic multiarm star polylactide with hyperbranched polyethylenimine as core: A systematic reinvestigation. Polymer 2012, 53, 3900-3909. [CrossRef]

17. Biela, T.; Duda, A.; Penczek, S.; Rode, K.; Pasch, H. Well-defined star polylactides and their behavior in two-dimensional chromatography. J. Polym. Sci. Part A Polym. Chem. 2002, 40, 2884-2887. [CrossRef]

18. Kowalski, A.; Duda, A.; Penczek, S. Kinetics and mechanism of cyclic esters polymerization initiated with tin(II) octoate. 3. Polymerization of L,L-dilactide. Macromolecules 2000, 33, 7359-7370. [CrossRef]

19. Biela, T.; Kowalski, A.; Libiszowski, J.; Duda, A.; Penczek, S. Progress in polymerization of cyclic esters: Mechanisms and synthetic applications. Macromol. Symp. 2006, 240, 47-55. [CrossRef]

20. Tsuji, H. Quiescent crystallization of poly(lactic acid) and its copolymers-based materials. Adv. Polym. Sci. 2019, 283, 37-86. [CrossRef]

21. Tsuji, H.; Miyase, T.; Tezuka, Y.; Saha, S.K. Physical properties, crystallization, and spherulite growth of linear and 3-arm poly(L-lactide)s. Biomacromolecules 2005, 6, 244-254. [CrossRef]

22. Hao, Q.; Li, F.; Li, Q.; Li, Y.; Jia, L.; Yang, J.; Fang, Q.; Cao, A. Preparation and crystallization kinetics of new structurally well-defined star-shaped biodegradable poly(L-lactide)s initiated with diverse natural sugar alcohols. Biomacromolecules 2005, 6, 2236-2247. [CrossRef]

23. Wang, L.; Dong, C.M. Synthesis, crystallization kinetics, and spherulitic growth of linear and star-shaped poly(L-lactide)s with different numbers of arms. J. Polym. Sci. Part A Polym. Chem. 2006, 44, 2226-2236. [CrossRef]

24. Bojda, J.; Piorkowska, E.; Lapienis, G.; Michalski, A. Crystallization of star-shaped and linear poly(L-lactide)s. Eur. Polym. J. 2018, 105, 126-134. [CrossRef]

25. Lamberti, G. Flow induced crystallisation of polymers. Chem. Soc. Rev. 2014, 43, 2240-2252. [CrossRef]

26. Peters, G.W.M.; Balzano, L.; Steenbakkers, R.J.A. Flow-induced crystallization. In Handbook of Polymer Crystallization; Piorkowska, E., Rutledge, G.C., Eds.; John Wiley \& Sons, Inc.: Hoboken, NJ, USA, 2013; pp. 399-432. [CrossRef]

27. Wang, Z.; Ma, Z.; Li, L. Flow-induced crystallization of polymers: Molecular and thermodynamic considerations. Macromolecules 2016, 49, 1505-1517. [CrossRef]

28. van Meerveld, J.; Peters, G.W.M.; Hutter, M. Towards a rheological classification of flow induced crystallization experiments of polymer melts. Rheol. Acta 2004, 44, 119-134. [CrossRef]

29. Janeschitz-Kriegl, H.; Ratajski, E.; Stadlbauer, M. Flow as an effective promotor of nucleation in polymer melts: A quantitative evaluation. Rheol. Acta 2003, 42, 355-364. [CrossRef]

30. Mykhaylyk, O.O.; Chambon, P.; Graham, R.S.; Fairclough, J.P.A.; Olmsted, P.D.; Ryan, A.J. The specific work of flow as a criterion for orientation in polymer crystallization. Macromolecules 2008, 41, 1901-1904. [CrossRef]

31. Hsiao, B.S. Role of chain entanglement network on formation of flow-induced crystallization precursor structure. In Progress in Understanding of Polymer Crystallization; Reiter, G., Strobl, G.R., Eds.; Springer: Berlin/Heidelberg, Germany, 2007 ; pp. 133-149. [CrossRef]

32. Somani, R.H.; Yang, L.; Zhu, L.; Hsiao, B.S. Shish-kebab precursor structures in entangled polymer melts. Polymer 2005, 46, 8587-8623. [CrossRef]

33. Rhoades, A.; Pantani, R. Poly(Lactic Acid): Flow-Induced Crystallization. Adv. Polym. Sci. 2019, 283, 87-117. [CrossRef]

34. Zhong, Y.; Fang, H.; Zhang, Y.; Wang, Z.; Yang, J.; Wang, Z. Rheologically determined critical shear rates for shear-induced nucleation rate enhancements of poly(lactic acid). ACS Sustain. Chem. Eng. 2013, 1, 663-672. [CrossRef]

35. Xu, H.; Xie, L.; Hakkarainen, M. Beyond a model of polymer processing-triggered shear: Reconciling shish-kebab formation and control of chain degradation in sheared poly(L-lactic acid). ACS Sustain. Chem. Eng. 2015, 3, 1443-1452. [CrossRef]

36. Bojda, J.; Piorkowska, E. Shear-induced nonisothermal crystallization of two grades of PLA. Polym. Test. 2016, 50, 172-181. [CrossRef] 
37. Li, X.J.; Li, Z.M.; Zhong, G.J.; Li, L.B. Steady- shear- induced isothermal crystallization of poly(L-lactide) (PLLA). J. Macrom. Sci. Part B Polym. Phys. 2008, 47, 511-522. [CrossRef]

38. Kim, E.S.; Kim, B.C.; Kim, S.H. Structural effect of linear and star-shaped poly(L-lactic acid) on physical properties. J. Polym. Sci. Part B Polym. Phys. 2004, 42, 939-946. [CrossRef]

39. Fang, H.; Zhang, Y.; Bai, J.; Wang, Z. Shear-induced nucleation and morphological evolution for bimodal long chain branched polylactide. Macromolecules 2013, 46, 6555-6565. [CrossRef]

40. Wang, J.; Bai, J.; Zhang, Y.; Fang, H.; Wang, Z. Shear-induced enhancements of crystallization kinetics and morphological transformation for long chain branched polylactides with different branching degrees. Sci. Rep. 2016, 6, 26560. [CrossRef] [PubMed]

41. Michalski, A.; Łapienis, G. Synthesis and characterization of high-molar-mass star-shaped poly(L-lactide)s. Polimery 2018, 63, 488-494. [CrossRef]

42. Biela, T.; Duda, A.; Penczek, S. Enhanced melt stability of star-shaped stereocomplexes as compared with linear stereocomplexes. Macromolecules 2006, 39, 3710-3713. [CrossRef]

43. He, Y.; Wu, T.; Wie, J.; Fan, Z.; Li, S. Morphological investigation on melt crystallized polylactide homo- and stereocomplex by enzymatic degradation with proteinase K. J. Polym. Sci. Part B Polym. Phys. 2008, 46, 959-970. [CrossRef]

44. Huang, S.; Li, H.; Jiang, S.; Chen, X.; An, L. Crystal structure and morphology influenced by shear effect of poly(L-lactide) and its melting behaviour revealed by WAXS, DSC and in-situ POM. Polymer 2011, 52, 3478-3487. [CrossRef]

45. Righetti, M.C.; Gazzano, M.; Di Lorenzo, M.L.; Androsch, R. Enthalpy of melting of $\alpha^{\prime}$ - and $\alpha$ - crystals of poly(L-lactic acid). Eur. Polym. J. 2015, 70, 215-220. [CrossRef]

46. Sarasua, J.R.; Prud'Homme, R.E.; Wisniewski, M.; Le Borgne, A.; Spassky, N. Crystallization and melting behaviour of polylactides. Macromolecules 1998, 31, 3895-3905. [CrossRef]

47. Garlotta, D. A literature review of poly(lactic acid). J. Polym. Environ. 2001, 9, 63-84. [CrossRef]

48. Piorkowska, E.; Galeski, A. Overall crystallization kinetics. In Handbook of Polymer Crystallization; Piorkowska, E., Rutledge, G.C., Eds.; John Wiley \& Sons, Inc.: Hoboken, NJ, USA, 2013; pp. 215-236. [CrossRef] 